\title{
Lone-Actor Terrorist Target Choice
}

\begin{abstract}
Lone-actor terrorist attacks have risen to the forefront of the public's consciousness in the past few years. Some of these attacks were conducted against public officials. The rise of hard-to-detect, low-tech attacks may lead to more public officials being targeted. This paper explores whether different behavioral traits are apparent within a sample of lone-actor terrorists who plotted against high-value targets (including public officials) than within a sample of lone-actors that plotted against members of the public. Utilizing a unique dataset of 111 lone-actor terrorists, we test a series of hypotheses related to attack capability and operational security. The results indicate that very little differentiates those who attack high-value targets from those who attack members of the public. We conclude with a series of illustrations to theorise why this may be the case.
\end{abstract}




\section{Introduction}

Once they have decided to commit an attack, the lone-actor terrorist acts under a number of social, technical, financial, and practical constraints. Often, this requires abandoning an ambitious plan for something less complicated. These hurdles may reflect why terrorism has typically been largely a group-based phenomenon. The pooling of talent, resources, expertise and experience in a group setting likely helps mitigate the difficulties in successfully committing a terrorist attack. However, some lone-actor terrorists do manage to conduct successful attacks against high-value targets, including public officials. For example, in October 2014, Michael ZehafBibeau fatally shot a Canadian soldier on sentry duty at the Canadian National War Memorial in Ottawa. Zehaf-Bibeau then entered the parliament building through the main entrance. A constable noticed Zehaf-Bibeau's rifle and attempted to wrest it from him. Zehaf-Bibeau shot and wounded the constable. Chased by Royal Canadian Mounted Police officers, Zehaf-Bibeau ran towards the Library of Parliament, passing various committee rooms containing Members of Parliament, including the then Canadian Prime Minister, as well as the leader of the opposition. A shoot-out followed and Zehaf-Bibeau was killed. The attack illustrated the growing threat of ISIS-inspired lone-actors seeking to commit attacks against high-value targets.

Despite its remaining a low-base rate phenomenon, there has been a considerable amount of research on various aspects of lone-actor terrorism. A primary research endeavour has involved exploring the psychology and ideological motivations that underpin lone-actor terrorism. This has included specific analyses of the role of online radicalisation in motivational development and ideological change (Berntzen \& 
Sandberg, 2014; Borum, 2013; COT, 2007; Gardell, 2014; Gill \& Corner, 2015;

Corner, Gill \& Mason, 2016; Michael, 2012; Moskalenko \& McCauley, 2011; Peddell

et al, 2016; Spaaij, 2012; Springer, 2009; Weinmann, 2012). Other studies highlight the specific difficulties that lone actors pose to contemporary counter-terrorism practices (Bakker \& de Graaf, 2010; Barnes, 2012; Brynielsson et al., 2013; Carter \& Carter, 2012; Coffey, 2011; Hewitt, 2014; Meyer, 2013; Striegher, 2013). Yet others have utilized a range of datasets to outline the profile, or lack thereof, of lone actors accompanied by an analysis of pre-attack behaviours (COT, 2007; Eby, 2012; Gill et al., 2014; Gill, 2015a; Gruenewald et al., 2013; Jasparro, 2010; Meloy \& Gill, 2016; Spaaij, 2010; Teich, 2011). Finally, comparative analyses with analogous offender types have highlighted similarities and differences between lone actors and school shooters, mass murderers and group terrorists (Gill \& Corner, 2013; Gruenewald et al., 2013; Malkki, 2014; McCauley \& Moskalenko, 2014; McCauley et al., 2013).

This paper explores whether lone-actor terrorists who target high-value targets differ from those who purely attack members of the public. Are they better-trained, more flexible criminals, more operationally secure, less impulsive, and more heavily embedded within potentially rich sources of social support? Within the literature on lone-actor terrorism, the specific subjects of attack preparation and planning, and of attack commission, have received little attention. This paper undertakes a statistical analysis utilizing a unique sample of 111 lone-actor terrorists in order to answer these questions.

\section{Lone Actor Terrorist Attack Research}

There is not yet a distinct theme within the literature on lone actor terrorism that focuses specifically on attack preparation, though one would expect that increasing 
our understanding of what happens pre-attack will significantly strengthen preventative efforts (Appleton, 2014, p.136). Gill et al. (2014) found that lone actor attacks are "rarely sudden and impulsive" (p. 434), although anecdotal evidence of recent ISIS-inspired attacks suggests this may be changing. All studies agree that preparatory conduct is typical, though the degree to which individuals engage in it varies (Spaaij, 2010; 2012). Existing research is also generally in agreement that a low level of sophistication characterizes the weapons and methods used in lone-actor attacks (Bakker \& de Graaf, 2010; Jasparro, 2010; Barnes, 2012; Ackerman \& Pinson, 2014; Appleton, 2014).

The literature is also generally in agreement that the weapons most frequently used by lone actors are firearms, followed by bombs (COT, 2007; Gruenewald et al., 2013a; 2013; Jasparro, 2010; Spaaij, 2010; 2012; van der Heide, 2011). Some studies hypothesise that little training or expertise is required to use firearms, which can be easily acquired in certain countries (Jasparro, 2010; van der Heide, 2011). Constructing a successful explosive device is considerably more difficult, and lone actors seem less likely to have the requisite knowledge and expertise (Ackerman \& Pinson, 2014; Kenney; 2010). With regards to preference for firearms versus explosive devises, and to weapons choice more generally, it appears that there may be differences between lone- and group actors (Spaaij, 2012). Jasparro (2010), observing a further preference for vehicle-collision based attacks, suggests that lone actors, overall, make relatively more use of low-skilled, 'pragmatic' weaponry. Of course, weapon selection is not independent from target choice, as specific target characteristics will render the use of certain weapons more or less appropriate (Clarke \& Newman, 2006). With regards to target choice, people are the most commonly selected target, with the general public much more likely to be attacked than 
government officials or politicians, who are more likely to receive personal protection or work in protected environments (COT, 2007; Eby, 2012; Spaaij, 2010; 2012; van der Heide, 2011; Teich, 2013).

On aggregate, these findings present a picture of an attack preparation phase that is, in many cases, characterized by a low level of sophistication (relative to, for example, group-based terrorist incidents) and driven by a variety of ideological motives. However, what this accumulated research does not provide is an abundance of concrete details about the modi operandi of lone actors. One reason for this is that such data has, so far, not been captured in detail by quantitative analyses (COT, 2007). Another factor is the variety of attack styles that lone actors have displayed, the above observations aside; although most have used firearms, others have opted for explosives, while others still have adopted more unusual means, such as using cars to run over their victims (Eby, 2012). As Bakker and De Graaf (2010) have argued, lone actor attacks are characterized by a "wide variety in target selection, use of weapons and modus operandi" (p. 4).

\section{Predicting Target Choice}

The targets of terrorist attacks differ in terms of how exposed, vital, iconic, legitimate, destructible, occupied, near (to the offender), and easy they are (Newman and Clark, 2010). We might therefore expect those who target high-value targets (government, military etc.) to differ significantly in terms of their capabilities from those who target members of the public. Attacks on high-value targets, all things being equal, should be a more complex task. High-value targets such as military personnel, military infrastructure, police or politicians are more target-hardened than most areas frequented by the general public. Capacity to undertake an attack may draw upon a range of resources including individual skills, operational security, the offender's 
immediate life-experiences, network properties and behaviors directly related to attack-planning.

Lack of resources limits what terrorists can do (Boyns and Ballard 2004). Many studies depict human capital as the key resource (Asal and Rethemeyer 2008). Jackson (2001) argues that larger terrorist organizations should be better at adopting and effectively using new technologies. Asal and Rethemeyer (2008) demonstrate that larger organizations are typically more lethal. Another possibility to consider is that the size of an organizational component will have a differential impact depending on the type of attack that is carried out. The level of expertise that a type of attack demands should have an impact on how human resources affect the success of that kind of attack (Jackson 2009, 12-13). The level of technical expertise needed for a standard attack against members of the public for example could be considered low so the impact of having limited technical skills should be minimal. On the other hand, complex attacks demand a higher level of organization, expertise, and security (if you assume that complex attacks have the potential to be more spectacular in their consequences) (Jackson 2009, 12-13).

The more engagement with a wider group, the more likely the individual will have acquired the requisite knowledge to conduct an attack on a difficult target. Broader radicalized groupings are likely to contain more knowledge, and more knowledge may lead to a more sophisticated plot. Thus, group influence and total knowledge should be related positively to one another from this perspective. 
Separate from the knowledge argument is one based on experience. This is important on two fronts. First, actors may be constrained in terms of their technical attack capability. This appears to be a major problem for them. Gill (2015) provides a range of case examples illustrating that lone actors tend originally to plot large-scale attacks, but end up having to scale these down due to technical constraints or alternatively engage in a number of criminal activities in order to obtain the necessary materials. Previous experience of criminal activity may aid potential lone-actor terrorists by providing the know-how to obtain particular materials. Second, without a group of cooffenders, an individual may lack the psychological impetus to engage in a violent attack. The lone-actor terrorist James Kopp's recollection of his actions illustrates the sentiments involved: "To pick up a gun and aim it at another human being, and to fire, it's not a human thing to do. It's not nice. It's not pleasant. It's gory, it's bloody. It overcomes every human instinct". Military psychology shows that it is easier to develop the psychological capability to kill within a group setting (given the right conditions) than it is when going it alone (Grossman, 2005; Gill 2012). Within a cell of like-minded individuals, cognitive, evaluative and affective components of the group can impact and shape behavior. However, if the individual has a history of violence or experience in the military, such hurdles will have previously been surmounted, potentially leading to greater capability, potentially allowing an attack on a more difficult target. Thus, we expect that having more experience should allow a lone-actor to be more ambitious in his/her planning.

Gill et al. (2014) illustrated 'leakage' (the prior declaration by the actor of his beliefs and or intent to commit violence) as a regularly occurring antecedent behavior which 
is significantly linked to plots being intercepted. Given the difficulty surrounding the targeting of high-value targets, we might also expect greater operational security within such plots.

The existing literature on lone-actor terrorism characterizes many of the lone-actors as evidencing a number of recent stressors and risk factors that crystalize together prior to attack-planning. Given that high-value targets necessitate greater planning, we may expect that those lone-actors who have recently suffered stressors would also produce more spontaneous and less planned attacks.

From the above discussions, we hypothesize the following:

H1: Lone-actor terrorists with some form of prior relationship with extremist movements are more likely to attack high-value targets. H2: Lone-actor terrorist events against high-value targets will demonstrate a greater degree of pre-attack planning. H3: Lone-actor terrorists with a history of criminality, violence or military experience will more likely attack high-value targets. H4: Lone-actor terrorists plotting against high-value targets are significantly less likely to leak information in the build-up to the plot. H5: Lone-actor terrorists who experienced stressors in the previous six months were significantly more likely to attack members of the public. 


\section{Data and Method}

The dataset utilized for the subsequent analyses comprises Gill's (2015) codebook $^{1}$ and sample of 111 individuals who engaged in, or planned to engage in, a lone-actor terrorist event. All individuals were either citizens of, or carried out an attack in, the United States or Europe between 1990 and 2014, and were either convicted for their actions or died in the commission of their offence. The principal condition for inclusion as a lone-actor is whether the individual carried out or planned the offence alone. Individuals may have previously been a member of a group, or even trained and equipped by an organization, but their offence was attempted autonomously. The second condition for inclusion concerns ideology. To be considered for inclusion, an individual must have carried out, or planned to carry out, an attack in the name of some form of political ideology.

The codebook was developed based on extensive reviews of the literature and of existing codebooks concerning individuals who had committed a wide range of violent and non-violent offences, were victimized, and/or had engaged in high-risk behaviors. It includes over 185 variables spanning socio-demographic information, pre-event behaviors, event-specific behaviors, post-event behaviors and network related behaviors. Actor profiles were built using the LexisNexis archive of open source information, news and scholarly articles, public record depositories and loneactor biographies.

Three independent coders coded each data observation separately. Observations were then reconciled using a two-stage process (coder A with B, then coders A and B with

\footnotetext{
${ }^{1}$ For a more in depth explanation of the codebook construction, see Gill (2015, p19-22).
} 
C). When coder conclusions remained inconsistent, differences were resolved through consultation of the original sources, factoring in decisions regarding the reliability of sources, and the sources cited in the reports used. To aid this process, each source was plotted on a continuum of reliability (Table 1). Court transcripts and associated documents were deemed most reliable, as these documents recorded finalizations of judicial decisions. Competency evaluations, sworn affidavits and indictments were deemed reliable, as these were carried out post arrest and prior to trial, when initial investigations had been made. Statements (verbal or written) by the terrorist/affiliated group were deemed somewhat reliable, as there may be manipulated for propaganda purposes. Warrants and Expert Witness reports were also reasoned to be somewhat reliable, as warrants are produced prior to arrest, and like Expert Witness reports are subject to unreliability and bias. Media articles were then placed on a separate continuum within the less reliable end of the spectrum; personal opinion blogs were placed at the lower end and broadsheet newspapers at the upper end.

Table 1 Continuum of Reliability for Open-Source Data

\begin{tabular}{|c|c|c|c|c|c|}
\hline \multirow{2}{*}{$\begin{array}{l}\text { Least } \\
\text { Reliable }\end{array}$} & \multicolumn{2}{|c|}{ Partially Reliable } & Somewhat & Reliable & Very Reliable \\
\hline & & & Reliable & & \\
\hline \multicolumn{3}{|c|}{ Media Articles } & Manifestos & Competency & Trial Transcripts \\
\hline & & & & Evaluations & \\
\hline Internet & Tabloids & Broadsheets & Warrants & Sworn & Trial \\
\hline \multirow[t]{3}{*}{$\mathrm{B} \log \mathrm{s}$} & & & & Affidavits & Memorandums \\
\hline & & & Expert Witness & Indictments & \\
\hline & & & Reports & & \\
\hline
\end{tabular}


As target choice was the variable of interest in this investigation, actors who were apprehended in the planning phase of their attack, and who had not or did not subsequently declare a confirmed target choice, were removed from the analysis. This left 102 lone-actors in the study sample. Target choice was coded dichotomously as 'high-value' (HVT) or 'general public' using the same coding strategy as Asal et al. (2015). High-value targets were defined as government, business, military and political entities (including both personnel and buildings), and general public targets were defined as targets involving both discriminate and non-discriminate attacks on members of the public. Actors who targeted both high-value and general public entities were coded as HVT. We developed five aggregated variables related to target choice; network capabilities, attack planning, antecedent behaviors and experiences, leakage, and recent stressors.

For the aggregated variable 'network capabilities', we included: whether the individual had; a family member or close friend(s) who was involved in criminality (25\%), or a spouse or partner who had engaged with a terrorist movement (5\%); whether the individual had received hands-on training for the attack $(25 \%)$, interacted face to face with members of a wider terrorist network (41\%), interacted virtually with members of a wider terrorist network (29\%), involved others when procuring weaponry for the attack (17\%), or involved others in assembling constituents for IED related attacks (5\%), and whether the individual had command-and-control links with a wider organization or network (7\%).

For the variable 'attack planning' we included; whether the individual had engaged in dry runs of their attack (31\%), whether the individual had engaged in learning or 
developed plans for their attack through virtual (i.e. on-line) sources (43\%), and whether the individual had travelled (either domestically or internationally) to engage in preparatory activities $(26 \%)$.

'Antecedent behaviors and experiences' encompassed whether an individual had previously received military training (25\%), whether they had any previous criminal convictions (51\%), and whether they had engaged in any violent behavior prior to their attack $(45 \%)$.

The aggregated variable 'leakage' comprised pre-event declarations: whether the individual had produced letters or publically available statements (62\%), whether the individual had declared their intent or beliefs to family or friends (53\%), whether the individual had declared their intent or beliefs to a wider audience $(51 \%)$, whether at least one other person knew of the individual's grievance (76\%), or of their ideology (71\%), whether the individual had given a specific pre-attack warning (23\%), whether at least one other person knew of the individual's planning (35\%), whether the individual had expressed a desire to hurt people (69\%), and whether the individual had sought legitimization for their intended actions (15\%).

For the aggregation of 'recent stressors', we included situations that had occurred in the six months prior to the attack: being made unemployed (8\%), dropping out of education (3\%), experiencing the death of a close family member (1\%), work-related stressors (2\%), being denigrated(5\%), being the target of an act of prejudice/unfairness (5\%), being lied to or disrespected (4\%), being ignored or treated poorly by someone important to them (5\%), feeling that they were not cared about 
(5\%), being the victim of a verbal or physical assault (1\%), being a helpless victim (4\%), having personal relationship (10\%) and/or financial (8\%) problems, and experiencing stress $(17 \%)$.

\section{Results}

An initial comparison of lone-actors who made a definitive target choice found that 47\% chose a HVT, with $53 \%$ choosing a general population target.

To compare antecedent and event-related behaviors in lone-actors according to target choice, we conducted a bivariate tests using chi-square and Fisher's exact. Table 2 sets out the differences between the two groups in the five key aggregate variables of interest. 


\begin{tabular}{llc}
\hline & General & HVT \\
& public & $(\mathrm{n}=48)$ \\
& $(\mathrm{n}=54)$ & \\
\hline Network Behaviors & $72.2 \%$ & $64.6 \%$ \\
Planning Behaviors & $61.1 \%$ & $68.8 \%$ \\
Antecedent Behaviors and Experiences & $72.2 \%$ & $70.8 \%$ \\
Leakage Behaviors & $96.3 \% *$ & $83.3 \%$ \\
Stressors & $27.8 \%$ & $29.2 \%$ \\
\hline$*=<.05, * *=<0.01, * * *=<.001$ & & \\
\hline
\end{tabular}

Table 3 highlights the differences between the general public and HVT groups in terms of a range of characteristics. These are examined separately for each of the individual variables included in Table 2. Again chi square, and where appropriate, Fisher's exact Tests were used. Significant results are explained below.

\begin{tabular}{llc}
\hline Variable & \multicolumn{2}{l}{ Percentage Prevalence } \\
\hline & General & HVT \\
& public (n=54) & $(\mathrm{n}=48)$ \\
\hline Network Behaviors & $27.8 \%$ & $22.9 \%$ \\
\hline Family/Close Friends Involved in Criminality & $7.4 \%$ & $2.1 \%$ \\
Spouse Involved in a Violent Political Movement & & \\
\hline
\end{tabular}




\begin{tabular}{|c|c|c|}
\hline Received Hands on Training & $24.1 \%$ & $25.0 \%$ \\
\hline Face to Face Interaction with Members of a Network & $46.3 \%$ & $35.4 \%$ \\
\hline Virtual Interaction with Members of a Network & $31.5 \%$ & $27.1 \%$ \\
\hline Others Involved in Procurement of Weaponry & $14.8 \%$ & $18.8 \%$ \\
\hline Others Involved in IED Assembly & $5.6 \%$ & $4.2 \%$ \\
\hline Evidence of Command and Control Links with a Network & $9.3 \%$ & $4.2 \%$ \\
\hline \multicolumn{3}{|l|}{ Planning Behaviors } \\
\hline Undertook Dry Runs & $33.3 \%$ & $29.2 \%$ \\
\hline Online Learning & $35.2 \%$ & $52.1 \%$ \\
\hline Travelled for Preparatory Activities & $29.6 \%$ & $22.9 \%$ \\
\hline \multicolumn{3}{|l|}{ Antecedent Behaviors and Experiences } \\
\hline Military Experience & $24.1 \%$ & $25.0 \%$ \\
\hline Criminal Convictions & $48.1 \%$ & $54.2 \%$ \\
\hline History of Violence & $50.0 \%$ & $39.6 \%$ \\
\hline \multicolumn{3}{|l|}{ Leakage Behaviors } \\
\hline Produced Letters & $66.7 \%$ & $56.3 \%$ \\
\hline Made Statements to Family and/or Friends & $55.6 \%$ & $50.0 \%$ \\
\hline Made Statements to a Wider Audience & $51.9 \%$ & $50.0 \%$ \\
\hline Others were Aware of Actor's Grievance & $83.3 \%$ & $68.8 \%$ \\
\hline Others were Aware of Actor's Ideology & $77.8 \%$ & $62.5 \%$ \\
\hline Specific Warning of Intent Given & $22.2 \%$ & $22.9 \%$ \\
\hline Others Aware of Individual's Research/Planning & $31.5 \%$ & $39.6 \%$ \\
\hline Expressed a Desire to Hurt Others & $79.6 \% *$ & $56.3 \%$ \\
\hline Sought Legitimization for Grievance/Intentions & $18.5 \%$ & $10.4 \%$ \\
\hline
\end{tabular}

\section{Stressors}




\begin{tabular}{lll}
\hline Made Unemployed 6 Months Prior to Arrest/Event & $11.1 \%$ & $4.2 \%$ \\
Familial Death 6 Months Prior to Arrest/Event & $1.9 \%$ & $0.0 \%$ \\
Drop Out of Education 6 Months Prior to Arrest/Event & $3.7 \%$ & $2.1 \%$ \\
Work Related Stressor 6 Months Prior to Arrest/Event & $1.9 \%$ & $2.1 \%$ \\
Experienced being Degraded 6 Months Prior to Arrest/Event & $3.7 \%$ & $6.3 \%$ \\
Experienced being a Target of Prejudice 6 Months Prior to & $3.7 \%$ & $6.3 \%$ \\
Arrest/Event & & \\
Experienced being Disrespected 6 Months Prior to Arrest/Event & $3.7 \%$ & $4.2 \%$ \\
Felt Ignored 6 Months Prior to Arrest/Event & $3.7 \%$ & $6.3 \%$ \\
Felt as No One Cared 6 Months Prior to Arrest/Event & $5.6 \%$ & $4.2 \%$ \\
Experienced being a Victim 6 Months Prior to Arrest/Event & $1.9 \%$ & $0.0 \%$ \\
Experienced being a Helpless Victim 6 Months Prior to & $3.7 \%$ & $4.2 \%$ \\
Arrest/Event & & $8.3 \%$ \\
Problems with Personal Relationships 6 Months Prior to & $13.0 \%$ & $6.3 \%$ \\
Arrest/Event & & \\
Experienced Financial Problems 6 Months Prior to Arrest/Event & $7.4 \%$ & \\
Experienced Stress 6 Months Prior to Arrest/Event & $16.7 \%$ & \\
\hline$*$ s 05, ** = 0.01 *** = <.001 & & \\
\hline
\end{tabular}

$*=<.05, * *=<0.01, * * *=<.001$

The paucity of significant results highlights the limited differences between the two groups of lone-actors. Those who targeted the general public were significantly more likely to express a desire to hurt others. Individuals who targeted the general public showed a stronger, though non-significant pattern of leakage-related behaviors, with a higher prevalence of all relevant factors other than making others aware of their research and/or planning for their attack. Very few actors experienced stressful life events in the six months prior to their arrest/attack. The pattern of results indicates 
there to be little difference in the experience of stress between the actor types, with the same proportion reporting stress in each group (16.7\%). A greater proportion of who chose high-value targets learnt or prepared for their attack using the Internet $(52.1 \%$ v. $35.2 \%)$. Greater proportions of who chose general public targets made others aware of their grievance $(83.3 \%$ v. $68.8 \%)$ or ideology $(77.8 \%$ v. $62.5 \%)$, travelled for preparatory activities $(29.6 \%$ v. $22.9 \%)$, and conduct dry runs (33.3\% v. 29.2\%). However, these differences did not reach statistical significance.

\section{Discussion}

The results indicate that very little distinguishes those who plan to target the general public and those who plot against high-value targets. In only one of the five aggregated variables (leakage behaviours) was a significant difference found. Specifically, those who targeted members of the public were significantly more likely to leak aspects of their plot or information regarding their extremist beliefs. This offers support for hypothesis 4 (above). This has some implications for threat management and intelligence analysis. The leakage of intent is regularly used as a key warning indicator (Meloy and Gill, 2016): but the results here suggest it is more likely to lead to detection in cases where the general public are targeted. Nevertheless, at $83 \%$, leakage is still a common occurrence in high-value target plots. Other studies utilizing the same dataset have analysed the cases according to ideological boundaries (Gill, 2015) and the presence of mental health problems (Corner and Gill, 2015): issues to do with leakage appeared with the same prevalence across all of these subsets. 
The question then remains, how do intelligence and policing agencies encourage the recipients of leakage to come forward with this information. This is not an easy task. As Williams and Horgan's (2016) survey research shows, peers are unlikely to come forward, fearing they would get their friend in trouble. In some cases, there may be a complete disconnect between policing agencies and the communities within which there is a radicalisation problem. This is evidenced in the continuing attacks in France and Belgium through 2014 to date. There is no easy solution but to help build resilience in these communities around radicalisation awareness coupled with deep and continuing partnerships with front-line services (e.g. mental health, probation, education) which may spend a lot of face-time with potentially radicalised individuals and/or be the recipients of such leakage.

Surprisingly, target choice, in aggregate terms, had next to nothing to do with issues around capabilities and degree of planning. This confounds expectations derived from criminologically-oriented rational choice paradigms. Future research may shed light on their decision-making process in the form of cases studies examining actors who attacked high-value targets. For now though, we can use a series of illustrations to try understand how that particular target was chosen.

In May 2010, Roshonora Choudhry stabbed Labour Party MP Stephen Timms on behalf of the al-Qaeda movement. In her interview with police on the day of the attack, Choudhry was asked how she felt about what she had done that day. She replied; "I feel like I did what I'd planned to do...I feel like I've ruined the rest of my life. I feel like it's worth it because millions of Iraqis are suffering and I should do what I can to help them and not just be inactive and do nothing while they suffer". 
Because of the attack, Choudhry felt that she had "fulfilled my obligation, my Islamic duty to stand up for the people of Iraq and to punish someone who wanted to make war with them". As part of her preparations, Choudhry devised a list of Members of Parliament who voted for the 2003 invasion of Iraq. She researched the backgrounds of London-based Members of Parliament using the website 'They Work For You' which includes information on voting records. She apparently concentrated her research on Labour ministers Jim Fitzpatrick, Margaret Hodge, Nick Raynsford and Stephen Timms. Detectives later declared Timms her "sole and easiest target". This decision to attack Timms was made three to four weeks prior to the attack itself. Timms was Choudhry's local Member of Parliament. Her online research showed that Timms regularly voted with his government. She later told detectives that "he just voted strongly for everything, as though he had no mercy. As though he felt no doubts that what he was doing was right even though it was such an arrogant thing to do and I just felt like if he could treat the Iraqi people so mercilessly, then why should I show him any mercy?"

What is interesting about this case is that there is a mixture of religious/political and personal reasons behind the targeting of Timms. Choudhry had previously met Timms twice. The first occasion occurred three years prior to the attack on a trip organized by her secondary school when she was 17 . On the second occasion, Choudhry met Timms at his offices and sought a grant to continue her $£ 3290$ a year English degree at King's College London. She felt entitled to this grant because her father was unemployed and her family were relying on social welfare. Timms rejected her request and according to Newham Councillor Lucky Mish, Choudhry got "very angry". Soon after this rejection, she withdrew from University and filled her day by 
spending time online looking at radicalizing material. In terms of target choice and decision-making, we can make three conclusions. First, Choudhry also had a personal grievance against the target, one that predated any radicalization and attack planning. Second, she had awareness of the attack location from one of her previous meetings with Timms. Third, Timms' office was not as target hardened as the above theorizing assumes and very low-key attack planning and preparation was necessary to obtain access and carry out the attack.

Whilst Timms was a high-value target, his job as a member of parliament and his constituency work provided an opportunity for a very unsophisticated attack to succeed. The same is true for several other attacks on high-value targets such as Walter Leroy Moody's letter bombing campaign of various members and institutions of the U.S. judicial system and Miles Cooper's similar campaign against state institutions that Cooper associated with the rise of the surveillance state. The ease of access in the Timms case is also reminiscent of the murder of Dutch politician Pim Fortuyn who was shot six times in public following a radio interview.

In June 2009 Abdulhakim Mujahid Muhammad (formerly Carlos Bledsoe) conducted a drive-by shooting on soldiers outside of a U.S. military recruitment office in Little Rock, Arkansas, killing one and injuring one. In September 2007, he left the U.S. for Yemen ostensibly to learn Arabic. During this time, he apparently radicalized further. He desired entry into Somalia to obtain militant training. Before he could leave, Yemeni authorities arrested him in October 2008. He returned to the U.S and to his hometown of Little Rock in January 2009. Upon his return to the U.S., Muhammad began planning an attack. He researched potential targets online including military 
facilities, Jewish centers, a post office, a Baptist church and a childcare center. These targets were geographically spread and included Little Rock, Memphis, Nashville, Florence, Kentucky, Philadelphia, Baltimore and Washington D.C. He claims the eventual attack "wasn't part of Plan A. Plan A was aborted because of failed attacks in Tennessee and Kentucky". In Nashville Tennessee, his attempt to firebomb a Rabbi's house failed when the Molotov Cocktail bounced harmlessly off the window rather than smashing through it. In Florence, Kentucky a drive-by shooting at an Army recruitment center was called off when he realized it was closed as he arrived.

So, the eventual attack at "the Crusader Center in Little Rock was Plan B. And compared to what I had planned originally, it was like a grain of sand. One crusader dead, one wounded, 15 terrorized, big deal. Nidal Malik is the real Islamic Warrior, and my plan A was on that scale. It included Little Rock, Memphis, Nashville, Florence KY, Philadelphia, Baltimore, and was supposed to end in DC.” He also lamented his failure to obtain bomb-making training in Yemen or Somalia. "I wanted training in explosives, on how to make bombs and in particular, car bombs, and had I got this training my story would have ended a lot differently than it's going to end now. My drive-by would have been a drive-in, with none escaping the aftermath". This case highlights that the lack of human capital does not necessarily deter the would-be offender from his eventual target, but rather makes him opt for a practicable attack method. Rather than displacing his activities toward a much easier target, a search process was undertaken that sought the key vulnerabilities of a high-value target. 
Other lone-actors benefitted from the lack of situational crime prevention measures in place at the time their attack occurred. The theory outlined above presumes that such measures are routine but this was not always the case, particularly the offenders that emerged through the 1990's. In April 1995, Timothy McVeigh bombed the Alfred P. Murrah Federal Building in Oklahoma City. Heavily influenced by the attack on the J. Edgar Hoover FBI building in The Turner Diaries, McVeigh decided to bomb a government building. Unlike Turner's location in Washington DC, McVeigh wanted to hit the heartland of America. His initial list included possible targets in Arkansas, Missouri, Oklahoma, Arizona, and Texas. Ultimately, he chose the Alfred P. Murrah Federal Building in Oklahoma City because he understood that it held offices for the ATF, Drug Enforcement Administration, and Secret Service, thereby providing maximum federal government causalities. Additionally he believed the U-shaped glass building would be easily damaged with a bomb placed inside the "U." Three days prior to the attack, McVeigh parked the getaway car in an alley very close to the Murrah Building and placed a sign that said, "Not abandoned. Please do not tow. Will move by April 23 (needs battery and cable)." Current situational security measures would undoubtedly have marked this vehicle as suspicious and security procedures would have increased in the days afterwards and potentially stopped McVeigh from parking the bomb-laden truck at the empty front parking area of the Murrah building. Again, current target hardening measures like moving parking lots away from buildings and installing barriers to prevent vehicles getting close may have made this target unsuitable in McVeigh's prior cost-benefit analysis and displaced him elsewhere. In a similar vein, Anders Breivik was said to have expedited his attack on the government building upon hearing that new target-hardening security and parking procedures were about to be enacted at the site (Hemmingby \& Bjorgo, 2015). 
Some lone-actors did not necessitate the hypothesized factors because their routine activities gave them access to the targets they needed. This includes Arid Uka an employee at Frankfurt Airport who had (a) regular contact with U.S. Military passing through the Airport and (b) access to a firearm which he passed through the less rigorous security screening given to employees compared to that of civilian passengers. It also includes Nidal Malik Hasan, a U.S. Army psychiatrist, who had easy access to firearms and suitable targets via his day job at Fort Hood, Texas. Similarly, Sgt. Asan Akbar of the U.S. Army threw grenades at fellow soldiers at a military command center in Kuwait. Bruce Ivins managed to send anthrax spores via the mail system to several high value targets. His job allowed him access to these materials, thus negating much of the social capital theorized as necessary earlier. These cases potentially present the need for screening processes of employees at locations where high-value targets are likely to frequent regularly.

\section{Conclusion}

Whilst studies of large datasets on lone-actor terrorists and on low-likelihood events shed light on patterns, processes and sub-unit differences, case study analyses may shed more light on the intricate decisions and trajectories that led individuals to commit acts of grievance-fuelled violence (be it personal, political, religious or all of the above). Our large dataset analysis largely confounded expectations. Whilst theory suggests that attacks on high-value targets would involve greater human capital, technical experience and planning, the findings suggest these traits are just as likely to be found in those attacking softer targets. 
Our large dataset analysis allows us to determine that, among lone-actors, the decision to target a particular target (e.g. general public vs. high-value targets) occurs very early in the decision-making process, usually following grievance formation and establishment. From there, opportunities in terms of specific target and attack method are sought from a variety of sources, with large proportions of actors sourcing support (both sociological and logistical) from others. The results highlight the necessity to focus preventive efforts on pre-attack leakage and the network-related behaviors of lone-actors As this study has shown, whether a lone-actor successfully executes their initial attack plan against their desired target appears to be dependent upon their individual willingness to adapt their available abilities to their surroundings, opportunity and easy access to the chosen target and, to some extent, on pure luck in security agencies not interdicting their plots. 


\section{References}

Ackerman, G. A., and L. E. Pinson. (2014) "An Army of One: Assessing CBRN Pursuit and Use by Lone Wolves and Autonomous Cells." Terrorism and Political Violence 26, no. 1: 226-45.

Appleton, C. (2014). Lone wolf terrorism in Norway. The International Journal of Human Rights, 18(2), 127-142.

Asal, V., \& Rethemeyer, R. K. (2008). The nature of the beast: Organizational structures and the lethality of terrorist attacks. The Journal of Politics, 70(02), 437-449.

Asal, V., Gill, P., Rethemeyer, R. K., \& Horgan, J. (2013). Killing Range Explaining Lethality Variance within a Terrorist Organization. Journal of Conflict Resolution, 0022002713508927.

Bakker, Edwin, and Beatrice De Graaf. (2010) "Lone Wolves: How to Prevent This Phenomenon?" In Expert Meeting Paper, 1-8. The Hague: International Centre for Counter-Terrorism.

Barnes, B. (2012). Confronting the one-man wolf pack: Adapting law enforcement and prosecution responses to the threat of lone wolf terrorism. Boston University Law Review, 92(1613).

Berntzen, L. E. and Sandberg, S. (2014). "The Collective Nature of Lone Wolf Terrorism: Anders Breivik and the Anti-Islamic Social Movement." Terrorism and Political Violence, DOI: 10.1080/09546553.2013.767245 (published online Feb. 2014).

Borum, R. (2013). Informing Lone- Offender Investigations. Criminology \& Public Policy, 12(1), 103-112.

Boyns, D., \& Ballard, J. D. (2004). Developing a sociological theory for the empirical understanding of terrorism. The American Sociologist, 35(2), 5-25.

Brynielsson, J., Horndahl, A., Johansson, F., Kaati, L., Mårtenson, C., \& Svenson, P. (2013). Harvesting and analysis of weak signals for detecting lone wolf terrorists. Security Informatics, 2(1), 1.

Carter, J. G., \& Carter, D. L. (2012). Law enforcement intelligence: implications for self-radicalized terrorism. Police practice and research, 13(2), 138-154.

Clarke, R.V. \& Newman, G.R. (2006). Outsmarting the terrorists. New York: Praeger.

Coffey, K. (2011). Lone Wolf-Solo Terrorism and the Challenge of Preventative Prosecution, The. FIU Law Review, 7, 1.

Corner, E. and Gill, P. (2015) "A False Dichotomy? Lone Actor Terrorism and Mental Illness". Law and Human Behavior 39(1):23-34

Corner, E., Gill, P. and Mason, O. (2016) "Mental Health Disorders and the Terrorist: A Research Note Probing Selection Effects and Disorder Prevalence". Studies in Conflict and Terrorism 39(6): 560-568.

Eby, C. A. (2012). The nation that cried lone wolf: A data-driven analysis of individual terrorists in the United States since 9/11. Naval Postgraduate School Monterey CA Dept of National Security Affairs.

Gill, P. (2012). Terrorist violence and the contextual, facilitative and causal qualities of group-based behaviors. Aggression and Violent Behavior, 17(6), 565-574.

Gill, P. (2015). Lone-Actor Terrorists: A Behavioural Analysis. London: Routledge. 
Gill, P., \& Corner, E. (2013). Disaggregating terrorist offenders: Implications for research and practice. Criminology \& Public Policy, 12(1), 93-101.

Gill, P., Horgan, J., \& Deckert, P. (2014). Bombing Alone: Tracing the Motivations and Antecedent Behaviors of Lone- Actor Terrorists. Journal of Forensic Sciences, 59(2), 425-435.

Grossman, D.,(2005). On killing: The psychological cost of learning to kill in war and society. London: Bay Back Books

Gruenewald, J., Chermak, S., \& Freilich, J. D. (2013). Distinguishing "loner" attacks from other domestic extremist violence. Criminology \& Public Policy, 12(1), 65-91.

Hewitt, C. (2014). Law enforcement tactics and their effectiveness in dealing with American terrorism: Organizations, autonomous cells, and lone wolves. Terrorism and Political Violence, 26(1), 58-68.

Jackson, B. A. (2001). Technology acquisition by terrorist groups: threat assessment informed by lessons from private sector technology adoption. Studies in Conflict and Terrorism, 24(3), 183-213.

Jasparro, C. (2010). Lone wolf: The threat from independent jihadists. Jane's Intelligence Review, 3-4.

Kenney, M. (2010). "Dumb" yet Deadly: Local Knowledge and Poor Tradecraft among Islamist Militants in Britain and Spain. Studies in Conflict \& Terrorism, 33(10), 911-932.

Malkki, L. (2014). "Political Elements in Post-Columbine School Shootings in Europe and North America." Terrorism and Political Violence 26(1): 185-210.

McCauley, C. and Moskalenko, S. (2014). "Toward a Profile of Lone Wolf Terrorists: What Moves an Individual From Radical Opinion to Radical Action." Terrorism and Political Violence 26(1): 69-85.

Meloy, J.R. and Gill, P. (2016) "The Lone Actor Terrorist and the TRAP-18". Journal of Threat Assessment and Management 3(1): 37-52

Meyer, S. (2013) "Impeding Lone-Wolf Attacks: Lessons Derived from the 2011 Norway Attacks." Crime Science 2, no.6: 1-13.

Michael, G. (2012) Lone Wolf Terror and the Rise of Leaderless Resistance. Nashville: Vanderbilt University Press.

Moskalenko, S., \& McCauley, C. (2011). The psychology of lone-wolf terrorism. Counselling Psychology Quarterly, 24(2), 115-126.

Newman, G. R., \& Clarke, R. V. G. (2010). Policing terrorism: An executive's guide. Diane Publishing.

Peddell, D., Eyre, M., McManus, M. and Bonworth, J. (2016). "Influences and vulnerabilities in radicalised lone-actor terrorists: UK practitioner perspectives." International Journal of Police Science \& Management. doi:10.1177/ 1461355716638686.

Spaaij, R. (2010). "The Enigma of Lone Wolf Terrorism: An Assessment," Studies in Conflict and Terrorism, 33(9): 854-870.

Spaaij, R. (2012). Understanding Lone Wolf Terrorism. Springer Briefs in Criminology.

Springer, N. R. (2009). Patterns of radicalization: Identifying the markers and warning signs of domestic lone wolf terrorists in our midst. Naval Postgraduate School Monterey CA Dept of National Security Affairs.

Striegher, J. L. (2013). Early detection of the lone wolf: advancement of counterterrorism investigations with an absence or abundance of information and 
intelligence. Journal of Policing, Intelligence and Counter Terrorism, 8(1), 3553.

Teich, Sarah. (2013) "Trends and Developments in Lone Wolf Terrorism in the Western World: An Analysis of Terrorist Attacks and Attempted Attacks by Islamic Extremists". Herzliya: International Institute for Counter-Terrorism, 2013.

Van der Heide, L. (2011). Individual Terrorism: Indicators of Lone Operators. Doctoral Thesis. Available from: http://igitur-archive.library.uu.nl/studenttheses/2011-0902-

02354/MA\%20Thesis\%20Liesbeth\%20van\%20der\%20Heide.pdf 